\title{
Computer Aided Drawing software delivered through Emotional Learning. The use of Emoticons and GIFs as a Tool for Increasing Student Engagement.
}

\author{
Matteo Zallio \\ Technological University Dublin, matteo.zallio@tudublin.ie \\ Damon Berry \\ Technological University Dublin, damon.berry@tudublin.ie
}

Follow this and additional works at: https://arrow.tudublin.ie/teapotcon

Part of the Computer Engineering Commons

\section{Recommended Citation}

Zallio, M. \& Berry, D. (2018) Computer Aided Drawing software delivered through Emotional Learning. The use of Emoticons and GIFs as a Tool for Increasing Student Engagement, 32nd International BCS Human Computer Interaction Conference (HCl) 4-6 July 2018, Belfast, United Kingdom. DOI: 10.14236/ewic/ $\mathrm{HCl} 2018.75$

This Conference Paper is brought to you for free and open access by the tPOT: People Oriented Technology at ARROW@TU Dublin. It has been accepted for inclusion in Conference Papers by an authorized administrator of ARROW@TU Dublin. For more information, please contact arrow.admin@tudublin.ie, aisling.coyne@tudublin.ie, gerard.connolly@tudublin.ie.

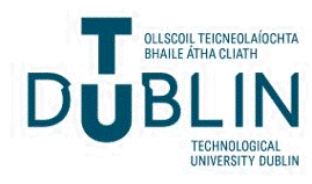




\title{
Computer Aided Drawing software delivered through Emotional Learning. The use of Emoticons and GIFs as a tool for increasing student engagement.
}

\author{
Dr. Matteo Zallio \\ Dublin Institute of Technology - tPOT group \\ Kevin st. Lower - Dublin - Ireland \\ Matteo.zallio@dit.ie
}

\author{
Dr. Damon Berry \\ Dublin Institute of Technology - tPOT group \\ Kevin st. Lower - Dublin - Ireland \\ Damon.berry@dit.ie
}

\begin{abstract}
It is known that one of the key factors for many manufacturing companies, who are involved in the design and development process, is represented by the quality of the skills, capacity and experience of computer-aided design draftsman and designers. This means that effective, up-to-date and engaging training has to be performed by teachers and instructors, since the early stage lectures for novice engineering students. When learners are engaged and actively participate in the training process, then this transfers in to a high, deep level of learning, quality of the learnt topics and perceived passion. The following question arises, "how can the process of improving the absorption of information concerning Computer Aided Drawing software lectures, through an iterative, engaging process, be facilitated?". This work represents a fist attempt to analyse and discuss, by using some of the main theories related to the learning process, how student engagement can be positively affected by using emoticons and GIFs during CAD software lectures.
\end{abstract}

Constructivism, CAD software, Emotional Learning, Facilitator, Emoticons, Contemplative Pedagogy, Human Computer Interaction.

\section{INTRODUCTION: AN OVERVIEW ON CAD LECTURING}

It has been well documented that humans learn better through a compelling combination of hearing, seeing and hands-on experience that would improve the stimuli for an effective learning experience, rather than just through the use of hearing and seeing. (Alcorn, 2003).

It is also known that teachers, usually have to spend their time in various activities such as administration, lectures preparation, one to one discussion with students, lecturing, moving through the classroomrevision and question and answers (Achen et al., 2015). These commitments certainly affect the quality of the teaching process, in particular with practical topics such as technical graphics and CAD (Computer Aided Drawing) software lectures.

CAD lectures perfectly represent a situation where different aspects of theoretical and practical learning methodologies have to be applied in a compelling way. Students, especially from level 6 and level 7 (according to the Irish Framework of Qualifications) may incur in early stage learning issues, particularly when they have to approach for the first time a complex drawing software such as AutoCAD or Revit.

Based on the academic practice with two different classes, that have never used any CAD software before, this work tries to analyse and discuss, by using some of the main theories related to the Constructivist Theory of Learning and the Emotional Learning process, how student engagement (particularly at the early stage of the learning process) can be affected by using emoticons and GIFs in CAD lectures.

The main topic of interest concerns the application of an Emotional Learning approach (Goleman, 2004), that follows the statement of the Constructivism theory, in comparison with the Cognitivism methodology.

In these terms, it is interesting to know how possible is to engage students to effectively understand, learn, remember, participate and apply knowledge, with an AutoCAD software for technical drawings, in a professional way.

This work is particularly focused on the discussion of existing learning theories that can be applied in the lecturing practice of AutoCAD lessons to level 6 and level 7 students (two classes composed of 17 and 13 students) of the degree of Electrical Engineering at the Dublin Institute of Technology.

The teaching and learning practice is often based on commonly recognised approaches such as the Constructivism and the Cognitivism methodologies. Emotional Learning and contemplative pedagogy, can be used as theories to underline if the usage of contemporary "simplifiers" such as emoticons and 
GIFs, used during the teaching process, could enrich and increase the level of attention and engagement of different students.

\section{METHODOLOGY: EMOTIONAL LEARNING AND RELATED THEORIES}

One of the most common learning approaches is the Constructivist Theory of Learning (CTL) which offers a view on knowledge perception, processing and development of the teaching strategy (Kolb, 1984).

According to Piaget (Piaget, 1950) who is the founder of the Constructivism Theory, humans make meaning in relation to the interaction between their experiences and their ideas. The lecturer/teacher should adapt his role as a facilitator and a vehicle for the information, rather than just a teacher. The facilitator should help the learner (students) to catch his own understanding of the treated subject. In particular, Constructivism claims that people "construct" their own meaning by building on their previous knowledge and experience. "Constructs", according to Carlile et al., are representations of the world (Carlile et al., 2005). In a similar way we may think that visual facilitators (such as GIFs and emoticons) in the lecturing context may be associated as "constructs" and easily generate feelings and emotions that would improve the connection between teacher and student (Figure 1).

Different studies (Baron, 2009; Amaghlobeli, 2012; Danesi, 2016) outlined the key role of emoticons and graphical representations in digital communication, but not only. Younger generations are using more and more icons, GIFs and graphical representations while messaging or during visual communication mediated by a computer or technological devices.
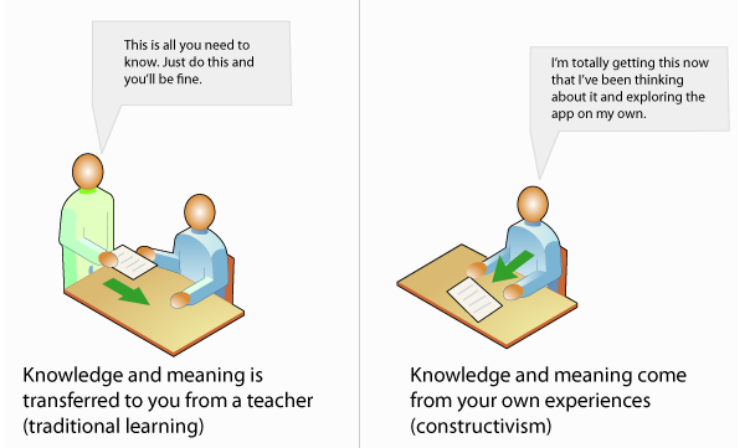

Figure 1: The Constructivism Theory of Learning.

According to Dresner \& Herring (2010), Vandergriff (2014) and Spina (2016), there are at least two other important pragmatic functions of emoticons and graphical representations, that are not necessarily mapped onto facial expressions:
- The function of social markers of familiarity and empathy, useful during the interaction process with students.

- The function of markers of the pragmatic force of a text, aimed at intensifying or downgrading its meaning, is particularly interesting when it is useful to increase the level of attention during a complex lecture.

By following these statements, it is possible to assume that the representation of concepts, text and information is slowly passing from a language composed of text and words to a communication vehicle composed of images and general graphics, such as GIFs, emoticons and recently animoticons.

This innovative type of communication, borrowed from the common language of teenagers and young adults in messaging conversation, has been applied, in this specific case, as a facilitator for improving and increasing certain stages of the learning process, during AutoCAD lectures.

A collateral, interesting teaching theory currently in use among a consistent number of teachers refers to the Cognitivism approach as a Pedagogical Philosophy that focuses on how the mind processes and uses information. Within Cognitivism, tasks are analysed and then broken down into smaller steps and information. The concepts are then taught from the simplest to the most complex, based on the learner's prior knowledge and according to the learning behaviour of students. Gagnè introduced a model which describes the factors that influence learning and that collectively may be called the conditions of learning (Gagnè, 1971). He particularly identified five main areas in which people learn and he developed a 9-tier hierarchy or sequence of learning based on cognitive principles, recognising that different instruction is required for different learning outcomes: Verbal information, Intellectual skills, Cognitive strategies, Motor skills, Attitudes.

Finally, Emotional Learning is recognised as a major element in teaching practice. It is known that long-term memory retention is greatly aided by the emotional associations of that memory, and memory loss occurs when their emotional associations are too painful (Carlile et al., 2005). Emotions are central to the interpersonal and intrapersonal domains in Gardner's multiple intelligences theory. Goleman has led to the development of a number of instruments designed to identify EQ or emotional intelligence (Goleman, 1996). One area of particular interest is the emotional intelligence of the teacher or facilitator in recognising and responding to the emotions and moods of students in order to facilitate engagement and motivation. Following Goleman example, the usage of emoticons and GIFs, has been applied, in order to stimulate the emotions such as hilarious and ironic feelings among young students. 


\section{DISCUSSION}

It has been noticed that when teaching subjects, such as AutoCAD to novice students, their engagement may vary and they may not be completely involved and comfortable while explaining the topic.

This is due to several aspects: passion in using personal computers and new software and more in general the engagement to quickly learn (or not) a new subject. The approach used in teaching this particular software, refers to the Constructivism methodology and has been reinforced by the use of some aspects of the Emotional Learning theory and the Contemplative Pedagogy. In particular, the use of facilitators such as emoticons, GIFs and graphical representations has been introduced in lectures in order to foster the achievement of a higher level of attention from the students and stimulate a creative learning process.

Figure 2 shows how the slideshow is usually characterized by a variable number of technical slides explaining the topic in details, with interruptions (highlighted in red) every 3 to 6 slides with an image, GIFs or graphical representation that help in increasing the attention and engagement with students.

As the Cognitivist theory is more based on transferring knowledge from a top level (teacher or lecturer) to the audience - differently from the Constructivism approach, where the teacher is placed more at the level of the audience - the usage of graphical representations and emotions can be perceived from the students as a way to stimulate memory, increase attention and improve empathy during the lecture. A further aspect that came out during the visual analysis of behaviour is that with a Cognitivist approach the lecturer is more entitled to use an "out of scheme" approach in teaching, because of the role in the class. With a Constructivist approach, there might be the risk of students to understand the content of a lecture in a less seriously way. It has been seen that depending on the selected teaching methodology, it is important to carefully select the number of emoticons and graphic representation used during a lecture, in order to keep the level of attention high and do not excessively distract students.

At the end of the lecturing period, when topics become more practical and the theoretical lessons have less impact in the course, there has been a decreased need of using facilitators during presentations. It is very likely that the usage of emotional facilitators at the beginning would be helpful to create a connection and stimulate empathy between teacher and learners.

By looking at the level of attention of the audience it is possible to confirm that it is easier for students to better understand certain topics after showing emoticons or GIFs. This finding has been confirmed by the majority of the students that expressed a positive verbal feedback at the end of the teaching period. This is an element that highly stimulate the attention and by levering on emotions, students are more likely to focus their attention after the given emotional stimuli.

\section{CONCLUSION}

The facilitators are not only useful for creating a special relationship between students and lecturer, but it has been seen that some of the students remember particular commands or functions of the software, because they were linked to a particular emoticon or GIF.

This is a sign that facilitators and in this case graphical representations of expressions, gestures and icons may be extremely useful not only for engaging students in an open relationship with the lecturer, according to the Constructivism theory, but also to improve students learning skills.

Some identified strategies such as the usage of contemporary, diffused facilitators (largely used among teenagers and young people) in the process of transferring knowledge in third level education, "critical incident" and storytelling can incorporate emotions along with the cognitive and narrative elements of experience therefore promoting deeper levels of meaning (Carlile et al., 2005). This preliminary work cannot be considered as a deep study, but would throw the basis to further investigate a strategy and a methodology on how emotional learning can be affected by using icons, emoticons, animoticons, GIFs and graphical representations for developing an engaging, friendly learning process with the new generation of students. 


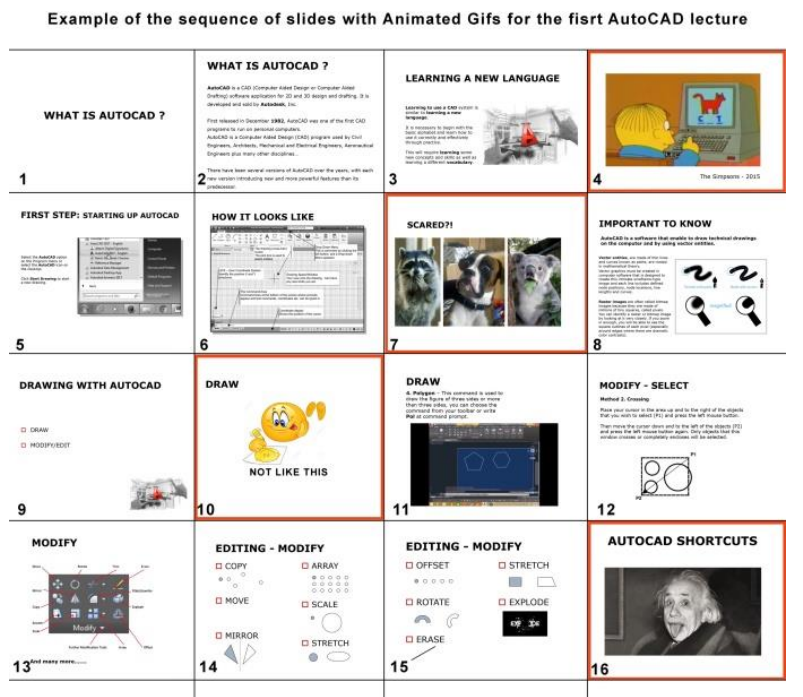

Figure 2: Sequence of slides from the first presentation to Level 6 students that shows the insertion of GIFs and graphical representations every 3 to 6 slides.

\section{REFERENCES}

Achen, R. and Lumpkin, A. (2015). Evaluating Classroom Time through Systematic Analysis and Student Feedback. International Journal for the Scholarship of Teaching and Learning, 9(2).

Alcorn, Christopher G. (2003) Improving Student Knowledge through Experiential Learning, A Hands-On Statics Lab at Virginia Tech.

Amaghlobeli, N. (2012). Linguistic features of typographic emoticons in SMS discourse. Theory and Practice in Language Studies, 2(2), pp. 348--354.

Baron, N. (2009). The Myth of Impoverished Signal: Dispelling the Spoken Language Fallacy for Emoticons in Online Communication. In $\mathrm{J}$. Vincent \& L. Fortunati (Eds.), Electronic Emotion: The Mediation of Emotion via Information and Communication Technologies. Bern: Peter Lang, pp. 107-135.

Carlile O. \& Jordan A. (2003) It works in practice but will it work in theory? The theoretical underpinnings of pedagogy. In: Emerging Issues in the Practice of University Learning and Teaching.

Danesi, M. (2016). The Semiotics of Emoji. The Rise of Visual Language in the Age of the Internet. London: Bloomsbury.

Dresner, E., Herring, S.C. (2010). Functions of the Nonverbal in CMC: Emoticons and Illocutionary Force. Communication Theory, 20(3), pp. 249-268.

Gagné, Robert (1971). Learning hierarchies. NJ: Prentice Hall. pp. 63-84.
Goleman, D. (1996). Emotional Intelligence. London: Bloomsbury Press.

Goleman, D. (2004). Building academic success on social and emotional learning. New York: Teachers College Press.

Kolb, D.A. (1984). Experiential Learning: Experience as the Source of Learning and Development. Englewood Cliffs, NJ: Prentice Hall.

Jordan, A., Carlile, O., \& Stack, A. (2008). Approaches to learning: A guide for teachers. McGraw-Hill, Open University Press: Berkshire.

Piaget J. (1950) The Psychology of Intelligence. New York: Routledge.

Piaget, J. and B. Inhelder (1967). A Child's Conception of Space (F. J. Langdon \& J. L. Lunzer, Trans.). New York: Norton (Original work published 1948)

Ramsey F. Hamade, Hassan A. Artail \& Mohamad Y. Jaber (2005) Learning Theory as Applied to Mechanical CAD Training of Novices, International Journal of Human- Computer Interaction, 19:3, 305-322, DOI: 10.1207/s15327590ijhc1903_2.

Spina, S., Cancila, J. (2013). Gender issues in the interactions of Italian politicians on Twitter: Identity, representation and flows of conversation. International Journal of Crosscultural Studies and Environmental Communication, 2(2), pp. 147--157.

Vandergriff, I. (2014). A pragmatic investigation of emoticon use in nonnative/native speaker text chat. Language@ Internet, 11. 